\title{
Cooperative breeding in the Lake Tanganyika cichlid Julidochromis ornatus
}

\author{
Dik Heg · Zina Bachar
}

Received: 31 May 2005/ Accepted: 17 March 2006/Published online: 11 May 2006

(C) Springer Science+Business Media B.V. 2006

\begin{abstract}
Cooperative breeding has been described for several cichlids from the genus Julidochromis (Perciformes: Cichlidae) under laboratory conditions, but field evidence is scarce. Here we describe the breeding system of the cichlid Julidochromis ornatus (Boulenger) in Lake Tanganyika (Zambia). Groups defended a breeding shelter under a large flat stone. Smaller group members stayed and fed under or close to the stone, actively guarded by the larger group members. Six out of 28 groups were newly established by breeders, joined by subordinates from a large pool of independent fish (comprising $50-70 \%$ of the total population), and four groups were seen to dissolve during a total of 77 observation days. Breeding groups consisted of a large breeding male and female with zero to five smaller subordinates (average 2). Larger breeders and subordinates were found in larger groups. All group members participated in territory defence and -maintenance, but the breeders were only present at the shelter $48 \%$ of the time, in contrast to the subordinates which guarded the breeding shelter $94 \%$ of the time. Smaller group members showed submissive behaviours to larger group
\end{abstract}

\footnotetext{
D. Heg $(\bowtie) \cdot$ Z. Bachar

Department of Behavioural Ecology, Zoological

Institute, University of Bern, CH-3032

Hinterkappelen, Switzerland

e-mail: dik.heg@esh.unibe.ch
}

members. We conclude subordinates in J. ornatus are helpers, but we did not find evidence that helpers increased the group's current reproductive success. Personal observations combined with a literature review revealed at least 19 species of Lake Tanganyika cichlids show evidence of cooperative breeding, entirely confined to the substrate breeding tribe of the Lamprologini (24\% of 80 species in total): 2 Chalinochromis spp., 5 Julidochromis spp., 12 Neolamprologus spp. More effort should be put into detecting cooperative breeding in American and Asian substrate breeding cichlid species.

Keywords Reproductive success $\cdot$ Reproductive behaviour ' Social behaviour ' Helping behaviour · Group size

\section{Introduction}

Cooperative breeding, wherein subordinates assist dominant breeders raising a brood, is a widespread phenomenon in birds, mammals and several invertebrates, notably the Hymenopterans (Stacey and Koenig 1990; Duffy 1996; Choe and Crespi 1997; Solomon and French 1997; Cockburn 1998). Albeit fish are the most speciose group found within the vertebrates, and show advanced levels of social behaviour, including cooperative territory defence and mate sharing, nonetheless 
cooperative breeding has rarely been described (Taborsky 1994). In a comprehensive literature review, Taborsky (1994) found only eight fish species having 'helpers-at-the-nest': Betta brownorum and B. persephone, and six species from the family Cichlidae, tribe Lamprologini, all endemic to Lake Tanganyika. Descriptive and experimental data on such breeding systems are known from only two species of Lake Tanganyika cichlids: Neolamprologus pulcher (sub- or sister species of $N$. brichardi the 'Princess of Burundi', formerly known as Lamprologus brichardi, see Grantner and Taborsky 1998, for comments on the species-status of these species; Taborsky and Limberger 1981; Taborsky 1984, 1985; BalshineEarn et al. 1998; Dierkes et al. 1999; Balshine et al. 2001; Skubic et al. 2004; Stiver et al. 2004; Heg et al. 2004a, b; authorities are given in the Appendix, except when mentioned) and the dwarf snail-shell cichlid N. multifasciatus (Rossiter 1993; Sato and Gashagaza 1997; Kohler 1998; Schradin and Lamprecht 2000, 2002). Data on the other Lake Tanganyika cichlids showing similar behaviour is either absent or very limited (e.g. Awata et al. 2005; Heg et al. 2005).

The purpose of this paper is, first, to describe the cooperative breeding system of one of these less well studied cichlids, Julidochromis ornatus (Kalas 1976; Hattori 1993; Taborsky 1994; Kawanabe et al. 1997; Konings 1998; Awata and Kohda 2004; Awata et al. 2005). Second, we review the literature on the incidence of cooperative breeding in Lake Tanganyika cichlids, and identify species where cooperative breeding has been described, or where cooperative breeding is suspected to occur (e.g. from observations on fish held in aquaria), but more detailed observations are needed. Both enterprises depend critically on the definition of cooperative breeding employed, i.e. what facts are considered evidence for the occurrence of cooperative breeding in a certain species? Ligon and Burt (2005) define cooperative breeding as '...social units composed of two or more breeding [individuals], plus one or more (often presumed) non-breeding "helpers-at-thenest'.' (see also Brown 1987 who lists 13 types of cooperative breeding systems).

We will follow this definition but have three clarifying comments to make, which have imme- diate bearing on our study. First, the definition leaves the possibility open that more than two individuals are reproducing. Ligon and Burt (2005) proceed by using the restricted definition of cooperative breeding, wherein helpers are nonbreeders, i.e. showing true alloparental care. Employing this restricted definition to a population where some groups have reproducing helpers, whereas others have non-reproducing helpers (see for examples Magrath et al. 2005), we would end with the following situation: (a) we would need to take an arbitrary cut-off point, e.g. proportion of groups with non-breeding helpers, from a reasonable sample of groups and populations, to reach a verdict whether the species is a 'true' cooperative breeder or not; (b) detailed genetic paternity and maternity analyses are needed before we can judge whether a certain species is a 'true' cooperative breeder; (c) the definition whether a species is a cooperative breeder might depend on the study population, study groups and time-periods wherein genetic analyses have been conducted, since helper reproduction may vary through space and time (e.g. Magrath et al. 2005). We think this is undesirable and rather opt for a broad definition of cooperative breeding, wherein we leave the possibility open that (sometimes) more than two individuals within a group are contributing offspring. Actually, this broad definition has also been used in most other comparative studies of cooperative breeding in e.g. birds (e.g. Ligon and Burt 2005 use a large number of bird species in their analyses, but in the majority of species no data on reproduction by helpers is available), exactly for the above mentioned reasons $(a, b, c)$.

Second, the definition implies that helpers assist the current brood. Several types of helping behaviours may be involved which either directly or indirectly influence the growth and/or survival of the brood (e.g. Arnold et al. 2005). In case of cichlids, these include digging at the breeding shelter, fanning and cleaning the brood, guarding the brood, chasing egg and offspring predators (Taborsky 1984).

Third, the definition does not refer to any of the ultimate (fitness) causes and consequences of group living and helping behaviour to the various group members. Helpers may sometimes benefit 
or harm the fitness prospects of the breeders in the group, depending on ecological circumstances (e.g. Komdeur 1994). Helping behaviour may often accrue no noticeable direct benefits to the breeders ('helper effect', e.g. because breeders reduce their workload when assisted by helpers, Balshine et al. 2001), although future benefits, like increased survival and future productivity, may be notoriously difficult to detect (Dickinson and Hatchwell 2005). Potentially, group size, reproductive partitioning, parental and helping behaviours may all be the outcome of both interand intrasexual cooperation and conflict, modified by e.g. relatedness, the relative and absolute competitive abilities of the various group members and the ecological circumstances. Thus, the fitness consequences for each group member may vary accordingly, and may lead to no benefits of group living to certain individuals compared to non-group living individuals.

Employing these criteria and using our knowledge of other cooperatively breeding cichlids (see references above), a cichlid species shows evidence for cooperative breeding when (1) subordinates assist breeders in raising a brood, i.e. show behaviours likely to increase the fitness of the brood when at the same time these behaviours are unlikely to increase fitness directly e.g. the survival of the subordinates (but the net effect might not increase the fitness of the brood, if breeders e.g. reduce their workload accordingly); (2) subordinates show submissive behaviours to the breeders, if not and the subordinates apparently engage in reproduction, the breeding system may be better described as a communal breeding system (a special case of cooperative breeding); (3) if (2) applies and same-sex reproducing individuals show no parental care, the breeding system may be better described as e.g. a dominant-satellite system, or sneaker male-territorial male system, as found in many species of fishes (Taborsky 1994).

In this paper, we present data on habitat and breeding site selection, group composition, body length and sex of group members, and parental-, spacing- and social behaviours in J. ornatus. Recently, Awata et al. (2005) have shown that both male and female subordinates in J. ornatus are usually unrelated to the breeders, both may participate in varying degrees in reproduction, and groups with subordinates tend to produce more offspring than single breeding pairs. We complement their findings by showing, first, that $J$. ornatus groups show the typical group compositions found in other cooperatively breeding cichlids, with a large dominant breeding pair and up to several smaller sized subordinates (see also Heg et al. 2005). Second, subordinates show the same helping and social behaviours as subordinates in other cooperatively breeding cichlids do, including chasing of egg and offspring predators and submissive behaviours towards the breeders. Third, we show that subordinates may join breeding pairs to help, which may account for the low relatedness found between subordinates and breeders (Awata et al. 2005).

Finally, based on the definition of cooperative breeding above and the types of helping behaviours and group compositions shown by all well studied cooperatively breeding cichlids (see references above, Heg et al. 2005 and this paper), we evaluate which Lamprologine cichlid species show evidence of cooperative breeding. For this purpose, we conducted a literature survey including less accessible papers, we gathered personal observations and correspondence from both the field and captive populations on the majority of the 80 Lamprologine species. We conclude with a preliminary mapping of the emergence of cooperative breeding in these cichlids (Sturmbauer et al. 1994), to argue for a multiple origin of cooperation in this lineage and to target future directions of research.

\section{Methods}

Study site and subjects

Our main study site lies at the south tip of Lake Tanganyika, at Kasakalawe near Mpulungu, Zambia $\left(8^{\circ} 46.849^{\prime} \mathrm{S}, 31^{\circ} 04.882^{\prime} \mathrm{E}\right)$. Cichlids were studied by SCUBA diving from 2 February to 21 April 2003. The main study site was a sandy area, with rocks half submerged in the sand, at 9.0$11.5 \mathrm{~m}$ depth. The present observations were conducted at a site dominated by two 'colonies' of $N$. pulcher and $N$. savoryi both occurring at very 
high densities. The habitat at our main study site has no layers of stones or boulders inaccessible to divers. All substrate breeding cichlids and their breeding shelters were easy to find and observe. $J$. ornatus is a particular conspicuous species, with its black-and-whitish longitudinal stripes, which facilitated locating even the very small individuals or individuals not associated with a breeding shelter. In contrast, our second study site at Nkumbula Island, ca. $2 \mathrm{~km}$ from Kasakalawe, near Mpulungu had a lot of sub-structuring: patches of large boulders $(>1 \mathrm{~m}$ diameter) were interspersed with patches of gravel and shell debris and patches of layered stones; quite similar to other studied populations of J. ornatus (Hattori 1993). Locating all breeding groups at this study site appeared difficult, since fish could hide between the boulders, and therefore no attempt was made to find all groups and estimate breeding densities at Nkumbula in the present study.

\section{Detection and mapping of breeding groups}

The main study area at Kasakalawe $\left(1708 \mathrm{~m}^{2}\right)$ was systematically surveyed for breeding groups using a $2 \times 2 \mathrm{~m}$ grid made with ropes $(32 \times 42 \mathrm{~m}$, plus two adjoining areas of $10 \times 10 \mathrm{~m}$ and $12 \times 22 \mathrm{~m}$, respectively). All potential breeding shelters (i.e. large stones with shelter underneath) were mapped, marked and controlled for breeding activity (i.e. presence of subordinates and offspring or apparent digging activity). We are convinced we detected all breeding groups in the main study area ( $n=23$ groups). Breeding shelters were invariably located under large, usually flat, stones and we measured the length and height of this stone in a sub-sample of the breeding groups using a ruler. Additional groups just outside the main study area were also marked and individuals measured and observed to increase sample sizes ( $n=5$ groups). At the second study site, Nkumbula Island, only four breeding groups were located at $2.3-2.5 \mathrm{~m}$ depth, and at three shelters stone measurements were taken.

Interspersed between the groups, numerous non-breeding individuals were seen. Non-breeders included fish of all sizes, presumably including both sexually mature and immature individuals. Hence, to avoid confusion with the small presumably non-breeding group members, we further refer to all non-group members as 'independents' (instead of non-breeders).

\section{Body measurements and sexing}

Within 1 week of the discovery of a breeding group, members of the breeding group (except the offspring, see below) were caught using tent nets with the help of the anaesthetic clove oil (also known as Eugenol, Kreiberg 2000) dissolved in ethanol. Tent nets were conical nets, at the base $1 \mathrm{~m}$ in diameter fitted with lead weights, at the top fitted with a small buoy. One part clove oil was dissolved in four parts $70 \%$ ethanol, and transported underwater in $25 \mathrm{ml}$ syringes. The tent net was placed over the breeding shelter as soon as all group members were present, and the dissolved clove oil was injected under the stone slab (10-25 ml depending on the size of the slab). Clove oil was highly effective in immobilising the fish, recovery occurred within $5 \mathrm{~min}$ and no adverse effects on subsequent behaviour were detected. We measured body length (standard length SL to the nearest $0.5 \mathrm{~mm}$ ) of all caught fish, sexed fish by close inspection of the genital papilla (only possible for individuals $>20 \mathrm{~mm} \mathrm{SL}$, and some individuals escaped before sexing). Subsequently, all fish were individually marked by fin clipping the dorsal-(5 positions) and/or anal fins (3 positions) in unique combinations for each size class, allowing future individual identification. All clipped fins had regrown at the end of the study period, and no adverse effects were detected from clipping, like desertion from the group/area or fungal infections. Group members larger than or equal to $20 \mathrm{~mm} \mathrm{SL}$, excluding the breeding male and female, were defined as 'subordinates'. Subordinates showed digging, brood guarding, territory defence, and submissive behaviour towards the breeders at the breeding shelters, and were not chased from the breeding site by the breeders.

All group members smaller or equal to $20 \mathrm{~mm}$ SL were defined as offspring, i.e. these individuals were usually hiding under the breeding shelter and rarely engaged in social interactions (D. Heg \& Z. Bachar, personal observations). Offspring were counted by turning up the breeding shelter 
stone every week, where they were found swimming upside down on the stone surface (see also Kuwamura 1986; Konings 1998; Brichard 1999). Their sizes were estimated with a ruler and cohorts of approximately equal SL were assigned to the same brood. At the end of the study period all remaining offspring were caught using a tent net and clove oil as described above, and measured to the nearest $0.5 \mathrm{~mm}$ SL using a ruler. In total, 203 group members were caught and measured.

Additionally, we caught, measured, marked and released 131 independents (75 at Kasakalawe and 56 at Nkumbula). Independents were chased into gill nets or transparent plastic tubes (one end open, one end sealed, $20 \mathrm{~cm} \times 40 \mathrm{~cm}$ length) and moved to a hand-net for measuring etc., before they could entangle or harm themselves in the gill net or the plastic tube.

\section{Reproductive success}

In 20 groups at Kasakalawe, we determined the total reproductive output over at least a period of 9 days (mean $\pm \mathrm{SE}=29 \pm 3$ days, range $=9-47$ days). We summed all offspring produced over all broods in that period, including pairs producing no offspring, to calculate the productivity per week.

Productivity should increase with the level of protection a group might provide to the eggs and young. We expected the level of protection to increase with (a) group size (i.e. more members available to chase away egg predators and piscivores), (b) standard length of the male and the female breeder, and/or (3) standard length of the largest subordinate in the group (i.e. larger group members might be able to chase away larger sized piscivores).

\section{Focal behavioural observations}

Focal observations were conducted on individually marked group members for $10 \min (n=37$ individuals: 10 breeding females, 9 breeding males, 13 male subordinates, 4 female subordinates, plus one subordinate we were not able to sex) in the Kasakalawe population only, selected at random from all the groups within the main study area. The observations were conducted during the daytime (between 08:53 and 16:47). To avoid pseudo-replication, all individuals were only observed once. We recorded the maximum distance moved from the shelter (using our grid lines as reference) and the proportion of the total observation time they spent within $50 \mathrm{~cm}$ from the shelter for the analyses of spacing behaviour. Additionally, we recorded the frequency of digging and carrying sand from the breeding shelter, the frequency of aggressive behaviours (including overt attacks: bites, chases, mouth-fights; plus display aggression: frontal approaches, spreading of the opercula, head-down display and s-shaped bend directed at con- and heterospecific fishes), the frequency of submissive behaviours (tailquivering and zig-zag swimming) and 'appeasement' or socializing behaviour (soft-touch also called 'bumping' of the body of group-members). These behaviours are very similar in appearance to related social Lamprologine species (Taborsky et al. 1986; Heg et al. 2005), see for a detailed description of these behaviours Taborsky (1984, 1985). Frequencies were also calculated per time near the breeding shelter, but they will not be presented because they gave essentially the same results.

Cooperative breeding in other Lake

Tanganyika cichlids

We conducted a literature survey of Lake Tanganyika cichlids, and included some recent unpublished observations and personal communications, to update our understanding of the extent of cooperative breeding in these cichlids (see Appendix for the list of scientific species names).

\section{Data analyses}

All statistical analyses were performed using SPSS 11.0 with significance levels set at $\alpha=0.05$. We failed to catch all group members in four groups at Kasakalawe, as these groups had already (partly) dissolved before we could catch them all. We also failed to catch all the members of two groups at Nkumbula Island, as catching was more difficult due to the large number of hiding possibilities between stone slabs. These account for missing values in some of the 
analyses. Since the group sizes, the body sizes and the sex ratio of the group members did not differ between the two populations (all $P$ values $>0.1$ ), these data were lumped in all analyses. The observational data (time at shelter, distance from shelter, frequencies of different behaviours) were lumped for the two sexes, because none of them differed between males and females, neither within the breeders, nor within the subordinates (all $P$ values $>0.4$ ).

\section{Results}

Breeding densities and breeding shelter selection

The breeding density at Kasakalawe was 0.135 groups per $10 \mathrm{~m}^{2}$. Groups in both populations selected large flat stones as breeding shelters (Kasakalawe/Nkumbula, mean length \pm SD: 82.2/ $100.0 \pm 16.5 / 5.0 \mathrm{~cm}$, range: $53 / 95-123 / 105 \mathrm{~cm}$; and height: $17.3 / 27.3 \pm 5.8 / 2.5 \mathrm{~cm}$, range: $11 / 25-30 /$ $30 \mathrm{~cm} ; n=26$ Kasakalawe, plus 3 Nkumbula groups).

Group formation and dissolution

During the 79 days study period at the Kasakalawe site, 6 of 28 groups were newly established at previously unoccupied large stone slabs, including one single breeding pair without subordinates; and five breeding pairs, joined by one subordinate each within one week after establishment (the SL of these subordinates was 24, 32, 33, 44 and $52 \mathrm{~mm}$ respectively; the $33 \mathrm{~mm}$ fish was marked 41 days earlier as an independent fish $6.2 \mathrm{~m}$ away from the new breeding site). At the same time, 4 of the 28 groups dissolved.

The first group dissolved one day after discovery just at the start of our study period and before the fish could be caught. In the second group the breeding male was no longer present at the beginning of the study period when we caught the group members (although present at the preliminary observations), and the breeding female plus one subordinate $(\mathrm{SL}=47.5 \mathrm{~mm}$ ) left the shelter area 16 days afterwards. Both breeders had left the third group before catching, leaving three subordinates at the shelter (SL $=36, \mathrm{~mm} 38 \mathrm{~mm}$ and $53.5 \mathrm{~mm}$ ) until the end of the study period. Finally, the fourth group was the only group which established and dissolved during the study period (breeding pair plus subordinate of $\mathrm{SL}=44 \mathrm{~mm}$, see above), after 17 days of shelter occupation (two independents were found near this shelter afterwards). We used the Life Table procedure in SPSS, which accounts for censored data, to calculate the duration of shelter occupancy based on the daily occupation rate ( $n=28$ groups): $68.3 \%$ were still occupied after 48 days, our longest time-interval between discovery and last observation, indicating that the expected median time of occupancy for any shelter is well above 48 days.

Group composition and body measurements

A typical group consisted of a breeding pair with one or two subordinates (Fig. 1a, mean group size \pm SD: $4.0 \pm 1.2$, range $=2-7, n=29$. Breeder males and females did not differ in their average body size (Table 1), and did not mate size-assortatively (Pearson $r=0.06, n=27, P=0.77$ ). Both breeder males and females were always larger than the largest subordinate group member (Fig. 1b, 26 out of 26 cases, excluding one breeding pair with no subordinates; Paired $t$-tests, df $=25, t=12.5$ and 10.8 respectively, both $P<0.001)$. Other group members were of very variable sizes (Fig. 2a). Subordinate males and females did not differ significantly in size (Table 1).

Large breeder males occupied territories with more group members compared to small breeder males (Pearson $r=0.45, n=27, P=0.02$; this relationship was not found in breeder females: $r=0.16, n=27, P=0.42)$. Moreover, it appeared that large breeders had relatively large subordinates as well, resulting in a complex relationship between group size, breeder body size and subordinate body size. This can be visualised and analysed by lumping the breeder males and females, since they did not differ significantly in size, into rank 1 , and ranking the subordinates according to size (descending) into rank 2, 3, 4 etc. and plot the average sizes for each group size separately (Fig. 1b; rank is equivalent to dominance rank, see section on Social Behaviour). The accompanying 

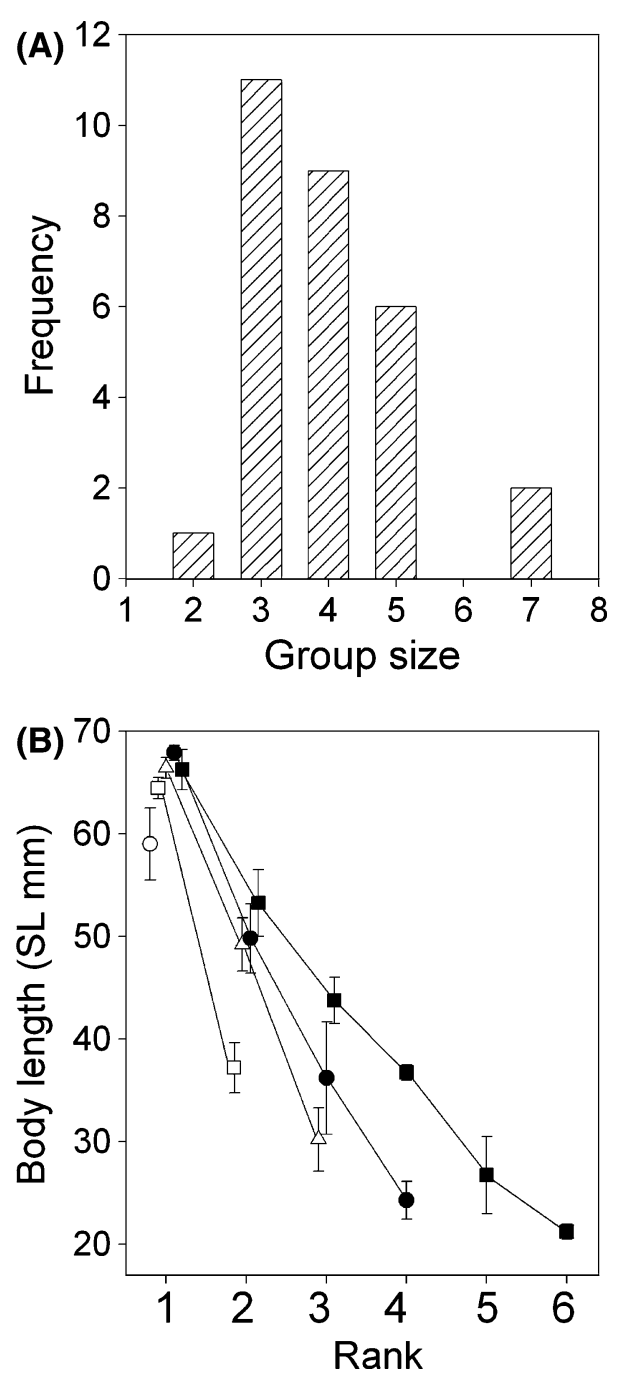

Fig. 1 (A) Frequency distribution of the group sizes in the breeding groups of J. ornatus (all fish $\geq 20 \mathrm{~mm}$ counted, $n=29$ groups). (B) Standard length of breeders and subordinates was related to the rank and the interaction between group size and the rank $(n=27$ groups and 80 individuals), showing that sizes of all group members increase with group size, resulting in large breeders being assisted by large subordinates and small breeders by small subordinates. Group size symbols are: white circles: 2, white squares: 3 , white triangles: 4 , black circles: 5 and black squares: 7 fish. Depicted are means \pm SE for the two breeders averaged (rank =1) and the subordinates $($ rank $=2-6)$

GLM revealed a significant effect of rank and the interaction between group size and rank on the SL ( $n=80$ and all $\mathrm{df}=1$, parameter estimates \pm SE of group size: $-0.21 \pm 1.35, \mathrm{p}=0.88$; of rank: $-24.84 \pm$ $2.85, P<0.001$; of group size*rank: $1.86 \pm 0.53$, $P=0.001$; with intercept: $82.70 \pm 6.22$ ).
As described above, subordinates were joining new breeding pairs from the pool of independents. Independents were available throughout the two populations, in a broad range of sizes (Table 1, compare Fig. 2b with Fig. 2a). The independents at Kasakalawe were significantly smaller (mean \pm SD: $49.5 \pm 11.5 \mathrm{~mm} \mathrm{SL}$, range = 31-70 $\mathrm{mm}, n=75)$ than the independents at Nkumbula $(58.9 \pm 10.4 \mathrm{~mm}$ SL, range $=38-77 \mathrm{~mm}$, $n=56$, ANOVA $\left.F_{1,129}=23.3, P<0.001\right)$. Note that no independents smaller than $31 \mathrm{~mm}$ SL were discovered at Kasakalawe, except the joining subordinate of $24 \mathrm{~mm}$ SL described above, despite intensive searching and the conspicuousness of these fish. Instead, all fish smaller than $31 \mathrm{~mm}$ occurred at the breeding shelters, i.e. were protected by larger group members. Similarly, no independents smaller than $38 \mathrm{~mm}$ SL were found at Nkumbula, but it must be noted this area was more difficult to survey due to the many hiding possibilities between the stones, meaning some small independents might went unnoticed.

It is very likely that joining subordinates are not a random sample of independents from the whole population for two reasons. First, re-sightings of individually marked independents at Kasakalawe indicated that they used a limited home range. The average distance between the site of marking and the site of re-sighting was $3.2 \mathrm{~m}(2.7 \mathrm{~m} \mathrm{SD}$, range $=0.0-9.8 \mathrm{~m}, n=15$ independents, multiple data-points per individual were averaged before analyses), and in this respect there were no modifying effects of sex ( $t$-test, $\mathrm{df}=12, P=0.19)$ nor SL (Regression, df $=1, P=0.34$ ). Second, there were significantly more male than female subordinates (36 versus 17, Binomial Test, $P=0.013$, seven group members could not be sexed), despite the breeders having an equal sex ratio and showing no sexual dimorphism (Table 1). The subordinate sex ratio was also significantly different from the sex ratio of the independents. For this analysis we compared the sexes of all fishes larger than $30 \mathrm{~mm}$, since independents were only found from $30 \mathrm{~mm}$ SL onwards (see Fig. 2, subordinates: 27 males vs. 11 females, independents: 59 males vs. 65 females, $\chi_{1}^{2}=6.6 P=0.01$, excluding seven unsexed independents). The fact that independent males were significantly smaller than independent females (Table 1) suggests that particularly 
Table 1 Body sizes of group and non-group members (independents) in J. ornatus (standard length SL: mean, SE and range) and results of three separate ANOVA tests for sex differences (each with df =1)

\begin{tabular}{lrlllll}
\hline Status & $n$ & Mean SL & SE & Range & \multicolumn{2}{l}{ Sex difference } \\
\cline { 5 - 7 } & & & & & $F$ & $P$ \\
\hline All breeders & 56 & 65.8 & 0.6 & $54-75$ & & \\
$\quad$ Breeder males & 27 & 65.6 & 0.8 & $57.5-72$ & 0.17 & 0.68 \\
$\quad$ Breeder females & 29 & 66.1 & 0.9 & $54-75$ & & \\
All subordinates & 60 & 38.2 & 1.5 & $20-60.5$ & & \\
$\quad$ Subordinate males & 36 & 39.3 & 1.8 & $21.5-59.5$ & 0.10 & 0.92 \\
$\quad$ Subordinate females & 17 & 39.0 & 3.2 & $20.5-60.5$ & & \\
All independents & 131 & 53.5 & 1.0 & $31-77$ & & \\
$\quad$ Independent males & 59 & 48.8 & 1.4 & $31-70$ & 17.4 & $<0.001$ \\
$\quad$ Independent females & 65 & 57.2 & 1.4 & $31.5-77$ & & \\
\hline
\end{tabular}

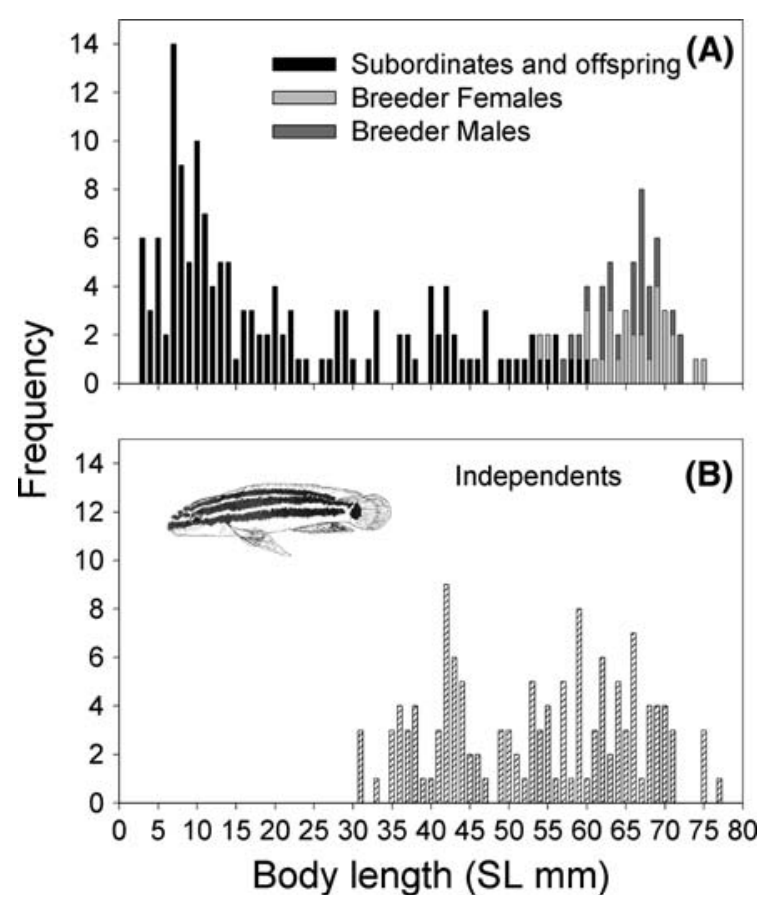

Fig. 2 Standard length of (A) group members and (B) independent $J$. ornatus $(0.5 \mathrm{~mm}$ values rounded downwards into $\mathrm{mm}$ classes). Inset shows adult individual (drawing after photo by Ad Konings)

relatively large independent males recruit as subordinates.

Time at the breeding shelter and distance travelled

Subordinates spent significantly more time at the breeding shelter (Table 2, Fig. 3) and ventured less far from the shelter than the breeders (Table 2, Fig. 3). Small subordinates stayed close to the shelter, while large subordinates were more similar to the breeders in the distance travelled from the shelter and the amount of time they spent near the shelter (Fig. 3).

There was no correlation between the size of the smallest group member (range $=10.0$ $47.5 \mathrm{~mm}$ ) and the proportion of time the breeders were within $50 \mathrm{~cm}$ from the shelter (Spearman $\left.r_{\mathrm{s}}=0.06, P=0.80, n=19\right)$ or the maximum distance breeders moved from the shelter $\left(r_{\mathrm{s}}=-0.02, P=0.93, n=19\right)$.

\section{Shelter maintenance and social behaviour}

Both subordinates and breeders showed digging behaviour, albeit at very low frequencies (Table 2). Digging behaviour was not related to status (Table 2) nor to body size SL (Spearman Correlations, digging per $10 \mathrm{~min}: r_{\mathrm{s}}=0.21$, $n=37, P=0.21)$. Similarly, no differences were detected in the frequencies of shelter defence behaviour between subordinates and breeders against conspecifics (Table 2). Conspecifics were never seen to venture close to or inside the breeding shelter, and therefore did not encounter the subordinates which tended to stay always close to or inside the shelter (see above). Aggression against heterospecific intruders was more common, but also these intruders were rarely seen to approach or enter the breeding shelter, in which case they were invariably attacked. Again, in this respect there were no differences between subordinates and breeders (Table 2). Defence behaviour was also not related to body size SL (Spearman Correlations, conspecifics per $10 \mathrm{~min}: r_{\mathrm{s}}=0.16, \quad n=37$, $P=0.33$, heterospecifics per $10 \mathrm{~min}: r_{\mathrm{s}}=0.20$, $n=37, P=0.23$ ). Fish species attacked included potential breeding shelter competitors (i.e. using 
Table 2 Mean percentage of time within $50 \mathrm{~cm}$, and maximum distance moved from the breeder shelter; and mean frequencies $( \pm \mathrm{SE})$ of behaviours per $10 \mathrm{~min}$ observation time; comparing breeders $(n=19)$ with subordinates $(n=18$; Mann-Whitney $U$-tests)

\begin{tabular}{|c|c|c|c|c|}
\hline \multirow[t]{2}{*}{ Parameter } & \multicolumn{2}{|l|}{ Status } & \multicolumn{2}{|c|}{ Mann-Whitney U-test } \\
\hline & Breeder & Subordinate & $U$ & $p$ \\
\hline \multicolumn{5}{|l|}{ Breeding shelter } \\
\hline Time $(\%)$ & $48 \pm 8$ & $94 \pm 3$ & 35 & $<0.001$ \\
\hline Maximum distance (m) & $3.20 \pm 0.29$ & $0.53 \pm 0.13$ & 11.5 & $<0.001$ \\
\hline Digging and carrying away sand & $0.39 \pm 0.27$ & $0.06 \pm 0.06$ & 153 & 0.31 \\
\hline \multicolumn{5}{|l|}{ Territory defence against } \\
\hline Conspecifics & $0.05 \pm 0.05$ & $0.00 \pm 0.00$ & 162 & 0.80 \\
\hline Heterospecific & $2.2 \pm 0.9$ & $1.2 \pm 0.9$ & 134.5 & 0.27 \\
\hline \multicolumn{5}{|l|}{ Types of species attacked } \\
\hline J. ornatus & 1 & 0 & & \\
\hline Shelter competitor ${ }^{a}$ & 19 & 10 & & \\
\hline Piscivores $^{\mathrm{b}}$ & 4 & 4 & & \\
\hline Egg predator ${ }^{\mathrm{c}}$ & 1 & 1 & & \\
\hline Scale eater ${ }^{\mathrm{d}}$ & 13 & 7 & & \\
\hline Other species & 5 & 2 & & \\
\hline
\end{tabular}

Also depicted are the total number of attacks against six types of intruders

${ }^{a}$ Neolamprologus pulcher and Telmatochromis temporalis

${ }^{\mathrm{b}}$ Lamprologus callipterus and L. tetracanthus: mainly young; Lamprologus lemairii and Lepidiolamprologus: young, subordinates and breeders

${ }^{\mathrm{c}}$ Telmatochromis vittatus

${ }^{\mathrm{d}}$ Perrisodus microlepis

similar breeding habitat), egg predators and piscivores (of both young and adults, Table 2).

We observed a limited number of social behaviours between group members. Small group members performed two types of submissive behaviours (zigzag swimming and tail quivering) towards larger group members. As well group members engaged in soft touches on the body which occurred more often when a breeder returned to the breeding shelter, e.g. between the returning breeder and the present breeder or between the returning breeder and the subordinate(s). Breeders were also observed on five occasions (in four different groups) to chase back to the breeding shelter a larger subordinate who had wandered far away $(>50 \mathrm{~cm})$. Breeders also bit these large subordinates $(45.5,49,50,54$ and $59.5 \mathrm{~mm} \mathrm{SL}$ ) who responded with submissive behaviours (see above).

\section{Reproductive success}

The average number of emerging young, 'broods', was 2.82 offspring $(0.35 \mathrm{SE}, n=34)$, but the modal brood size was one young only (median $=2$, Fig. 4). Productivity was highly skewed to the left, with an average of 0.98 offspring produced per week (0.24 SE, $n=20$ groups, median $=0.55$, range $=0.00-3.11$ offspring $/$ week $)$. A multiple regression with stepwise deletion of nonsignificant terms revealed only an almost significant effect of male SL on productivity $\left(R^{2}=0.19\right.$, estimates \pm SE: intercept $=-6.56 \pm 3.73$, male $\mathrm{SL}=0.12 \pm 0.057, P=0.058$ ), whereas group size, SL of the female and SL of the largest subordinate did not affect productivity $(P=0.74,0.84$ and 0.25 respectively).

Cooperative breeding in Lake Tanganyika cichlids

We identified 19 cichlid species showing evidence of cooperative breeding, entirely confined to the Lamprologini tribe ( $24 \%$ of 80 species in total): 2 Chalinochromis, 5 Julidochromis, and 12 Neolamprologus species (see Appendix). Two species show evidence for cooperative breeding behaviour in aquarium observations ( $N$. buescheri and 

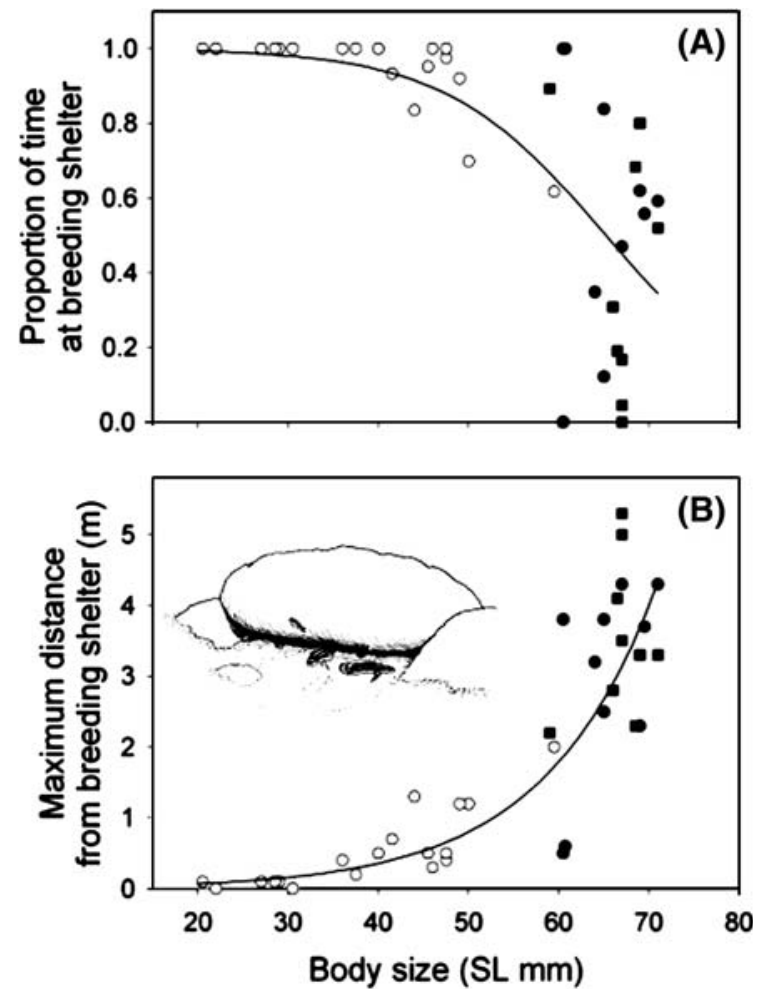

Fig. 3 (A) Proportion of time spent within $50 \mathrm{~cm}$ of the breeding shelter, and (B) maximum distance travelled from the breeding shelter for subordinates (white dots), breeder females (black dots) and breeder males (black squares) depended on standard length. Also depicted are (A) the logistic regression equation with coefficients \pm SE: proportion $=1 /\left(1+\exp ^{(-7.308 \pm 2.320+0.112 \pm 0.036 \times \mathrm{SL})}\right), \quad R^{2}=$ 0.51 ; and $(\mathbf{B})$ regression equation: $\ln [$ distance +0.1$]=$ $-3.62 \pm 0.27+0.071 \pm 0.005 \times \mathrm{SL}, R^{2}=0.86$. Inset shows typical breeding shelter with adult, subordinate and offspring

N. crassus: Büscher \& Heg, personal observations), including subordinates visiting breeding shelters and showing submissive behaviours to dominants (e.g. tail-quivering), which would raise the number of cooperatively breeding species to 21. Additional field observations on these two species and $N$. nigriventris are needed. The latter species shows prolonged parental care and offspring retention in the home territory, and might prove to be a cooperative breeder in at least some populations after more detailed field studies (Büscher, personal observations). Additional to these, more information is needed on the breeding biology of Lamprologus finalimus, L. stappersi,

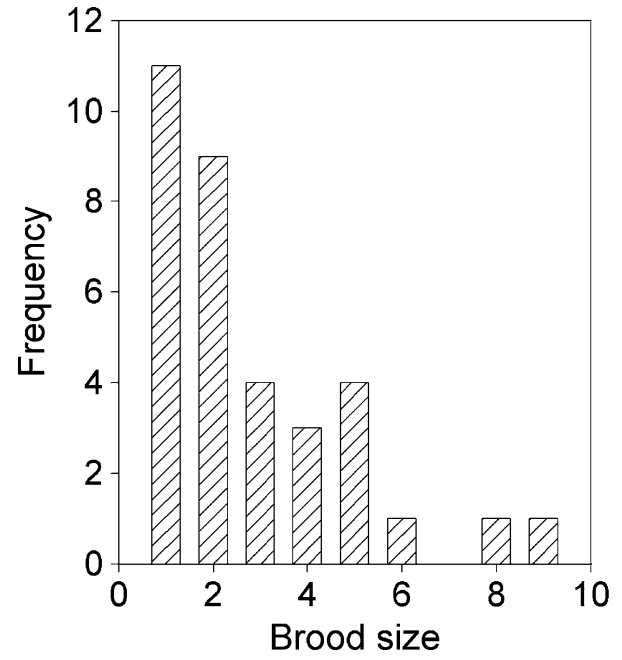

Fig. 4 Brood sizes (number of offspring emerging, $n=34$ broods of 20 groups) in J. ornatus

N. longicaudatus, and Telmatochromis brachygnathus.

Preliminary tracing of the incidence of cooperative breeding onto the molecular phylogeny suggests at least three separate origins of cooperative breeding in Lamprologines, once in Chalinochromis, once in the N. brichardi-complex and once in Julidochromis spp. (Fig. 5). A fourth lineage might consist of the two closely related cooperatively breeding dwarf cichlids, N. multifasciatus and $N$. similis, but their placement in the molecular phylogeny is still unresolved and we have tentatively placed these species close to the other snail-breeding Lamprologines (see 1 in Fig. 5), as suggested by the morphologically based phylogeny (Stiassny 1997). Finally, the $N$. brichardi-complex contains cooperatively breeding species ('helianthus' and 'olivaceous'-clades in Salzburger et al. 2002) interspersed with noncooperatively breeding cichlids (see Salzburger et al. 2002), suggesting either multiple origins, or secondary loss of cooperative breeding. Therefore, it is at present not possible to estimate the maximum number of separate origins of cooperative breeding in these cichlids. We await the completion of the Lamprologine phylogeny (S. Koblmüller and C. Sturmbauer, in preparation) to solve these points. 


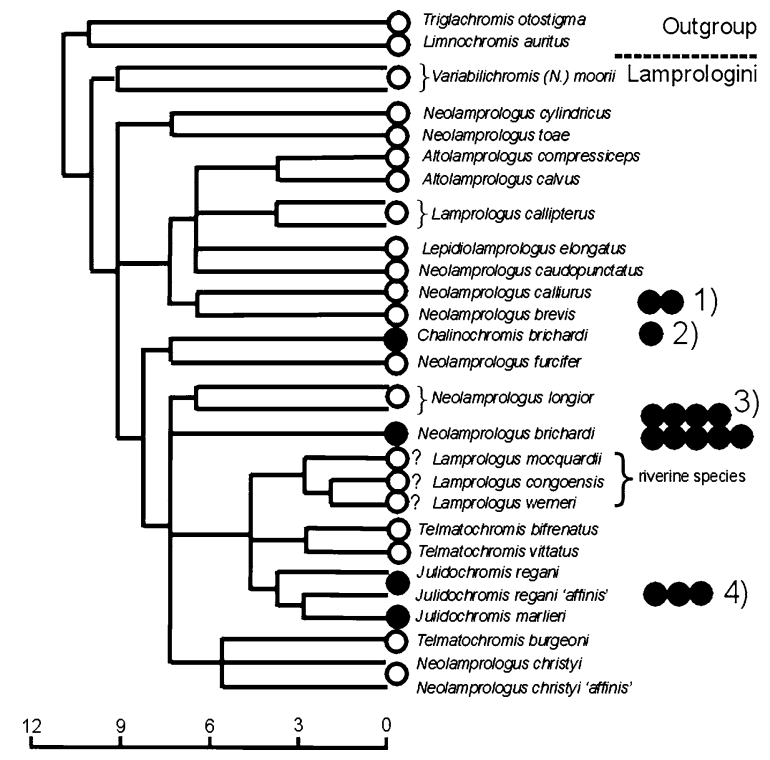

Fig. 5 Preliminary phylogenetic mapping of the incidence of cooperative breeding in the Lamprologini cichlid tribe (phylogeny modified after Sturmbauer et al. 1994: Figure 4 strict consensus tree). Black circles: cooperative breeding (see Appendix), white circles: non-cooperative breeding. The 15 cooperative species missing from the phylogeny are placed on the right to their nearest relatives (see text): (1) snail-shell breeding dwarf cichlids Neolamprologus multifasciatus and N. similis; (2) Chalinochromis popelini; (3) N. brichardi-complex (see Salzburger et al. 2002), (4) Julidochromis spp.

\section{Discussion}

Cooperative breeding in Julidochromis ornatus

Since subordinate $J$. ornatus showed all the behaviours that breeders showed to ensure reproductive success, i.e. digging, territory defence (against piscivores and egg predators), and spent a considerably amount of time guarding the breeding shelter, we conclude our operational classification of these fish as 'helpers' is justified (see also Awata et al. 2005). We did not find evidence that helpers increased the reproductive success of the breeders. Two papers have found correlative evidence that $J$. ornatus helpers may increase the reproductive success of breeders. First, Awata et al. (2005) reported more offspring in groups with helpers compared to groups without helpers, although the difference was just not significant. Second, a recent study showed a positive correlation between helper size and group reproductive success, controlling for confounding factors, suggesting that at least breeders with large helpers may benefit from the helper's presence (Awata et al. 2006). Helper removal experiments are currently analysed to solve these points (Heg and Bachar, in preparation). The social behaviours shown were similar to N. pulcher (Taborsky 1984, 1985) and N. savoryi (Heg et al. 2005), except that J. ornatus breeders showed apparent 'policing behaviour': chasing large helpers back to the shelter when helpers wandered too far of from the shelter. We do not know why breeders show this behaviour, but it might relate to the breeders 'needing' the helpers to protect the offspring against predators when the breeders are on foraging trips. Ranging behaviour and helping behaviours in J. ornatus were very similar to J. marlieri (Yamagishi and Kohda 1996): in this species helpers stayed 98\% of their time at the shelter, whereas breeders were only present $40 \%$ of the time.

Cooperative breeding groups in J. ornatus show several similarities and dissimilarities with other cooperatively breeding Lake Tanganyika cichlids, the major points are discussed in Heg et al. (2005). We will only highlight some striking results. First, J. ornatus breeding sites were at best intermittently occupied, whereby helpers joined new breeders, probably from the nearby pool of independents. This may explain the low relatedness between helpers and breeders reported for this species (Awata et al. 2005). No such group formation has been observed in $N$. pulcher (Taborsky and Limberger 1981; Balshine-Earn et al. 1998, 2001), although helper migration between groups does sometimes occur (Stiver et al. 2004; Dierkes et al. 2005). Genetic relatedness analyses suggest that both in N. pulcher (Dierkes et al. 2005) and N. multifasciatus (Kohler 1998) offspring remain at home for a prolonged time. Disappearing breeders may be replaced by the largest helpers in the group (Dierkes et al. 2005), or maybe by nearby large helpers and breeders leaving their territory. This seems not to be the case in $J$. ornatus, although it remains possible that limited dispersal of independents from their natal breeding site causes genetic population substructuring, such that helpers joining breeders are 
actually assisting close relatives (Awata et al. 2005 show that $14 \%$ of the helpers are related to either the male or female breeder).

Second, male body length correlated with group size and the size of the largest helper in the group, as it does in N. pulcher (Balshine et al. 2001), N. multifasciatus (Kohler 1998) and N. savoryi (Heg et al. 2005). On average, body length increased with group size and rank, which might be typical for most group living fish (e.g. also found in anemone fish Buston 2003; Mitchell 2003). This means that in all four cooperatively breeding cichlid species studied so far, large breeders defend territories with a large number of helpers, which tend to be large themselves as well. Such size-hierarchies may be maintained by statusdependent and strategic adjustments in growth (Heg et al. 2004b).

Cooperative breeding in Lake Tanganyika cichlids

We identified 19-21 species showing evidence of cooperative breeding in substrate breeding Lake Tanganyika cichlids (Lamprologini), whereas cooperative breeding was completely absent in all other substrate- and all mouth-breeding lineages in Lake Tanganyika (e.g. Haplochromini, Ectodini, Tropheini). We would like to stress that this listing should not be taken as the final verdict on the incidence of cooperative breeding in these cichlids, but should rather be taken as a starting point for more in-depth studies in the less well-known cichlids. However, we do have two notes of comfort. First, all three species we have studied both intensively in the laboratory and in the field show essentially similar types of group living and helping behaviour in both situations. This suggests that laboratory studies may be as worthwhile as field studies to establish whether subordinates are accepted in the breeder's territory and if yes, whether they are allowed to assist the breeders in raising offspring. Second, all cooperatively breeding Lamprologines show remarkable similarities in the types of helping and social behaviours performed, which should make detection of these target behaviours in the laboratory and field easy.

Stable, long-term territories, often accompanied by extended parental care, may be respon- sible for the high incidence of cooperative breeding in the Lamprologines, since these characters are often associated with substrate breeding in cichlids (e.g. Kawanabe et al. 1997) and have been hypothesised to be prerequisites, 'prestages', for the evolution towards cooperative breeding (e.g. Choe and Crespi 1997; Emlen 1997). We propose all these 'pre-stages' can be found in Lamprologine cichlids, which are currently not showing cooperative breeding. First, several species show extended parental care, but parents and offspring abandon the territory after offspring independence (e.g. Lepidiolamprologus spp., Kawanabe et al. 1997). Second, some species show extended parental care and have long-term territories, but the offspring leave or are chased from the territory after independence (e.g. Variabilichromis moorii, Kawanabe et al. 1997). Third, in Neolamprologus meeli (Poll) some adult offspring are philopatric (i.e. live inside/partly inside the territory of their parents) and interact with the parents, but do not assist the breeders in raising offspring (Sunobe and Munehara 2003).

Alternatively, our data and Awata et al. (2005) results on $J$. ornatus suggests there may be an alternative route towards cooperative breeding, wherein large subordinates are not retained offspring, but are unrelated individuals joining a breeding pair. Clearly, more field data on the other (supposedly) cooperatively breeding cichlids are needed (e.g. genetic relatedness between helpers and breeders, mode of group formation) to assess the likelihood and incidence of these two routes towards cooperative breeding (by reconstructing the timing of character evolution on a phylogenetic tree of the Lamprologines; see for example Goodwin et al. 1998).

Many of the American and Asian cichlid species and at least some of the riverine African cichlids share the above mentioned characters of Lamprologines (substrate breeding, territorial, extended parental care, see Goodwin et al. 1998; Barlow 2000). Therefore, one could expect that some of these species or at least populations might have developed cooperative breeding systems as well. However, no such evidence exists today, although other types of breeding systems have been described (e.g. Martin and Taborsky 1997). Of course, this might be due to a lack of field data on the 
breeding systems of many cichlids, in which case we suggest more effort should be directed in studying the breeding systems of the less well known cichlids. Alternatively, some ecological factor(s) specific to Lake Tanganyika may be responsible for this high incidence of cooperative breeding in Lamprologines. In any case, we regard the cooperatively breeding cichlids as a prime model system to test theories about how cooperation may have evolved and may be currently maintained.

Acknowledgments We express our deepest gratitude to C. Kapasa, H. Phiri, R. Shapola, L. Makasa, D. Sinyinza and C. Lukwesa from the Zambia Ministry of Agriculture, Food \& Fisheries for their continuous support of our project. We thank the Hasli crew, and the members of the
Lake Tanganyika Diving Expedition 2003 for their assistance. We are grateful to R. Eggler, S. Maurer and P. Stettler for co-organising the expedition. We thank M. Aibara, N. Duftner, M. Kohda, S. Koblmüller, K. Ota, C. Sturmbauer, M. Taborsky, and particularly H. Büscher for their lively input in the project and discussions of cichlid phylogeny. We thank Marcel Häsler, Ralph Bergmüller and the anonymous reviewers for comments on earlier versions of the manuscript. The project was supported by the Swiss National Science Foundation (SNF grant 3100064396 to Michael Taborsky). D.H. is supported by SNF grant 3100A0-108473.

\section{Appendix}

Evidence for cooperative breeding in Lake Tanganyika cichlids

\begin{tabular}{|c|c|c|c|c|c|}
\hline Species & $\mathrm{CB}$ & GL & M & $\mathrm{S}$ & References and comments ${ }^{\mathrm{a}}$ \\
\hline \multicolumn{6}{|l|}{ Chalinochromis } \\
\hline Ch. brichardi (Poll 1974) & Yes & Yes & Yes & $\mathrm{R}$ & $\begin{array}{l}\text { M. Kohda (personal communication); Brichard } \\
\text { (1999): offspring stay, }\end{array}$ \\
\hline Ch. popelini (Brichard 1989) & Yes & Yes & Yes & $\mathrm{R}$ & Brichard (1999): offspring stay \\
\hline \multicolumn{6}{|l|}{ Julidochromis } \\
\hline J. dickfeldi (Staeck 1975) & Yes & Yes & No? & $\mathrm{R}$ & Brichard (1999): offspring stay \\
\hline J. marlieri (Poll 1956) & Yes & Yes & Yes & $\mathrm{R}$ & $\begin{array}{l}\text { Kalas (1976), Yamagishi (1988), Yamagishi and } \\
\text { Kohda (1996), Sunobe (2000) }\end{array}$ \\
\hline J. ornatus (Boulenger 1898) & Yes & Yes & Yes & $\mathrm{R}$ & $\begin{array}{l}\text { This study, Kalas (1976), Hattori (1993), Awata } \\
\text { et al. (2005) }\end{array}$ \\
\hline J. regani (Poll 1942) & Yes & Yes & Yes? & $\mathrm{R}$ & Kalas (1976) , Kuwamura (1997) \\
\hline J. transcriptus (Matthes 1958) & Yes & Yes & Yes? & $\mathrm{R}$ & Kuwamura (1997) \\
\hline \multicolumn{6}{|l|}{ Neolamprologus $\mathrm{b}^{\mathrm{b}+}$} \\
\hline N. brevis (Boulenger 1899) & No & Yes & Yes & $\mathrm{O}$ & $\begin{array}{l}\text { Sato and Gashagaza (1997); M. Aibara ( } 2003 \\
\text { personal communication) individually marked } \\
\text { fish suggest high turn-over rate of territorial } \\
\text { males and satellite males, no stable groups } \\
\text { (Wonzye Point, Zambia) }\end{array}$ \\
\hline N. brichardi ${ }^{\mathrm{c}}$ (Poll 1974) & Yes & Yes & Yes & $\mathrm{R}$ & See references in Introduction \\
\hline 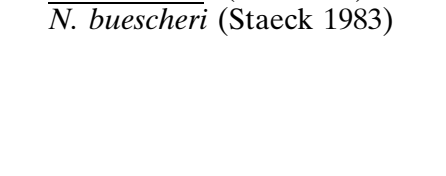 & Yes? & Yes & Yes & $\mathrm{R}$ & $\begin{array}{l}\text { Büscher ( } 1992 \mathrm{~d} \text { and personal communication). } \\
\text { H.H. Büscher and D. Heg, aquarium observa- } \\
\text { tions: adult offspring stay in and close to breed- } \\
\text { ing shelter and show submissive behaviours to } \\
\text { adult breeders }\end{array}$ \\
\hline N. calliurus (Boulenger 1906) & No & No & Yes & $\mathrm{O}$ & $\begin{array}{l}\text { Sato and Gashagaza (1997); M. Aibara (2003 } \\
\text { personal communication): variant of brevis at } \\
\text { sand-rock margins, shows ordinary polygyny } \\
\text { (Wonzye Point, Zambia) }\end{array}$ \\
\hline N. crassus (Brichard 1989) & Yes? & Yes & Yes & $\mathrm{R}$ & $\begin{array}{l}\text { H.H. Büscher (personal communication). H.H. } \\
\text { Büscher and D. Heg, aquarium observations: } \\
\text { adult offspring stay in and close to breeding } \\
\text { shelter and show submissive behaviours to adult } \\
\text { breeders }\end{array}$ \\
\hline N. falcicula (Brichard 1989) & Yes & Yes & Yes & $\mathrm{R}$ & $\begin{array}{l}\text { M. Taborsky (personal communication): mixed } \\
\text { colonies with } N \text {. pulcher (Tanzania); Brichard } \\
\text { (1999): lives in pairs or very small groups, usually } \\
\text { close to N. brichardi (Burundi) }\end{array}$ \\
\hline
\end{tabular}




\begin{tabular}{|c|c|c|c|c|c|}
\hline Species & $\mathrm{CB}$ & GL & $\mathrm{M}$ & $\mathrm{S}$ & References and comments $^{\mathrm{a}}$ \\
\hline N. gracilis (Brichard 1989) & Yes & Yes & Yes & $\mathrm{R}$ & $\begin{array}{l}\text { Woodland (2002), H.H. Büscher (personal com- } \\
\text { munication) }\end{array}$ \\
\hline N. helianthus (Büscher 1997) & Yes & Yes & Yes & $\mathrm{R}$ & H.H. Büscher (personal communication) \\
\hline$\overline{N . \text { marunguensis (Büscher 1989) }}$ & Yes & Yes & Yes & $\mathrm{R}$ & H.H. Büscher (personal communication) \\
\hline N. multifasciatus (Boulenger (1906) & Yes & Yes & Yes & $\mathrm{F}$ & $\begin{array}{l}\text { Rossiter (1993), Kohler (1998), Schradin and } \\
\text { Lamprecht }(2000,2002)\end{array}$ \\
\hline N. niger (Poll 1956) & Yes & Yes & Yes & $\mathrm{R}$ & $\begin{array}{l}\text { Konings (1998): young of previous broods are } \\
\text { tolerated in shelter (aquarium observations } \\
\text { only); Brichard (1999): co-dominant with } N \text {. } \\
\text { savoryi in main habitat }\end{array}$ \\
\hline N. nigriventris (Büscher 1992b) & No? & Yes & Yes & $\mathrm{R}$ & $\begin{array}{l}\text { Büscher (1992b and personal communication): } \\
\text { more field studies needed, offspring stay }\end{array}$ \\
\hline N. obscurus (Poll 1978) & No? & Yes & No & $\mathrm{R}$ & $\begin{array}{l}\text { Brichard (1999): offspring stay, but juveniles are } \\
\text { expelled from natal territory and defend com- } \\
\text { munal shelter }\end{array}$ \\
\hline N. olivaceous (Brichard 1989) & Yes & Yes & Yes & $\mathrm{R}$ & H.H. Büscher (personal communication) \\
\hline N. pulcher ${ }^{c}$ (Trewavas \& Poll 1952) & Yes & Yes & Yes & $\mathrm{R}$ & See references in Introduction \\
\hline N. savoryi (Poll 1949) & Yes & Yes & Yes & $\mathrm{R}$ & Kondo (1986), Heg et al. (2005) \\
\hline N. similis (Büscher 1992a) & Yes & Yes & Yes & $\mathrm{F}$ & $\begin{array}{l}\text { Barlow (2000): dwarf snail-cichlid, cooperative } \\
\text { breeder like N. multifasciatus; H.H. Büscher } \\
\text { (1992a and personal communication) }\end{array}$ \\
\hline N. splendens (Brichard 1989) & Yes & Yes & Yes & $\mathrm{R}$ & H.H. Büscher (personal communication) \\
\hline \multicolumn{6}{|l|}{ Telmatochromis* } \\
\hline T. dhonti & No? & Yes & Yes & $\mathrm{F}$ & $\begin{array}{l}\text { Sato and Gashagaza (1997): polygyny, probably } \\
\text { no cooperative breeding }\end{array}$ \\
\hline T. temporalis & No & Yes & Yes & $\mathrm{F}$ & $\begin{array}{l}\text { Katoh et al. (2005): occasional polyandry with } \\
\text { satellite males }\end{array}$ \\
\hline T. vittatus & No & Yes & Yes & $\mathrm{F}$ & $\begin{array}{l}\text { Ota and Kohda (2006): various breeding sys- } \\
\text { tems, including satellite and sneaker males, no } \\
\text { evidence for long-term stable group formation, } \\
\text { offspring retention or helpers }\end{array}$ \\
\hline
\end{tabular}

Only Lamprologine species were identified as potential cooperative breeders. Cooperative breeding was suspected in all species listed based on the main sources, which also excluded the species were extensive work has shown no evidence of cooperative breeding. Underlined are the species from the 'brichardi'-complex ('helianthus \& olivaceous-clades' from Salzburger et al. 2002). Definition of terms: CB 'Cooperative breeding': positive evidence that subordinates assist breeders raising a brood (e.g. territory defence, shelter maintenance and/or direct brood care), may include subordinates engaging in reproduction (e.g. Kohler 1998; Dierkes et al. 1999; Awata et al. 2005). GL 'Group living': lives in closely packed groups or colonies, indicative of cooperative breeding, but where group living might also be due to the presence of satellite males, polygyny, polyandry and/or polygynandry. M 'Multi-male or multi-female groups': lives in polygynous, polyandrous and/or polygynandrous groups, i.e. more than two breeders are (probably) engaged in reproduction. S 'Spawning inside snail': 'O' = obligate, ' $\mathrm{F}$ ' = facultative, ' $\mathrm{R}$ ' = rare or absent

a'Main sources: Büscher (1989-1998), Staeck and Linke (1981), Taborsky and Limberger (1981), Taborsky (1994), Brichard (1997, 1999), Kawanabe et al. (1997), Kuwamura (1997), Sato and Gashagaza (1997), Konings (1998). Comments: 'offspring stay' = offspring of successive broods stay in the natal territory

${ }^{\mathrm{b}}$ Insufficient information is available on (in brackets name giver(s)): N. finalimus (Nichols \& La Monte 1931), N. stappersi (Pellegrin 1927), N. longicaudatus (Nakaya \& Gashagaza 1995), and T. brachygnathus (Hanssens \& Snoeks 2003)

${ }^{c}$ Probably sub-species or sister-species, see Grantner and Taborsky (1998)

*Note that the genus Neolamprologus and Lamprologus are under continuing revision and some species have been formerly grouped under the latter name. Lamprologus meleagris vs. L. stappersi are treated as separate species by www.fishbase.org, but are more likely synonyms. The same applies to Telmatochromis burgeoni vs. T. temporalis

${ }^{\dagger}$ Grouped under non-cooperative breeders, but more information needed on (in brackets name giver(s)): N. longior (Staeck 1980) and N. wauthioni (Poll 1949). 


\section{References}

Arnold KE, Owens IPF, Goldizen AW (2005) Division of labour within cooperatively breeding groups. Behaviour 142:1577-1590

Awata S, Kohda M (2004) Parental roles and the amount of care in a bi-parental substrate brood cichlid: the effect of size differences within pairs. Behaviour 141:1135-1149

Awata S, Munehara H, Kohda M (2005) Social system and reproduction of helpers in the cooperatively breeding cichlid fish (Julidochromis ornatus) in Lake Tanganyika: field observations and parentage analyses. Behav Ecol Sociobiol 58:506-516

Awata S, Heg D, Munehara H, Kohda M (2006) Testis size depends on social status and the presence of male helpers in the cooperatively breeding cichlid Julidochromis ornatus. Behav Ecol 17:372-379

Balshine-Earn S, Neat FC, Reid H, Taborsky M (1998) Paying to stay or paying to breed? Field evidence for direct benefits of helping behavior in a cooperatively breeding fish. Behav Ecol 9:432-438

Balshine S, Leach B, Neat F, Reid H, Taborsky M, Werner N (2001) Correlates of group size in a cooperatively breeding cichlid fish (Neolamprologus pulcher). Behav Ecol Sociobiol 50:134-140

Barlow GW (2000) The cichlid fishes. Nature's grand experiment in evolution. Perseus Publishing, Cambridge (MA)

Brichard P (1997) Atlas der Tanganjikasee Cichliden. Band 1. Bede-Verlag, Ruhmannsfelden

Brichard P (1999) Atlas der Tanganjikasee Cichliden. Band 2. Bede-Verlag, Ruhmannsfelden

Brown JL (1987) Helping and communal breeding in birds. Ecology and evolution. Princeton University Press, Princeton

Büscher HH (1989) Ein neuer Tanganjika-Cichlide aus Zaire. Neolamprologus maraguensis n. sp. (Cichlidae, Lamprologini). Die Aquarien- und Terrarienzeitschrift 42:739-743

Büscher HH (1991a) Neue Schneckencichliden aus dem Tanganjikasee. Lamprologus meleagris n. sp. und $L$. speciosus n. sp. (Cichlidae, Lamprologini). Die Aquarien- und Terrarienzeitschrift 44:374-382

Büscher HH (1991b) Ein neuer Tanganjikasee-Cichlide aus Zaire. Neolamprologus pectoralis n. sp. (Cichlidae, Lamprologini). Die Aquarien- und Terrarienzeitschrift 44:788-792

Büscher HH (1992a) Ein neuer Cichlide aus dem Tanganjikasee. Neolamprologus similis n. sp. Die Aquarien- und Terrarienzeitschrift 45:520-525

Büscher HH (1992b) Neolamprologus nigriventris n. sp.: Ein neuer Tanganjikasee-Cichlide (Cichlidae, Lamprologini). Die Aquarien- und Terrarienzeitschrift 45:778-783

Büscher HH (1992c) Neolamprologus leloupi und N. caudopunctatus. DATZ 45:39-44

Büscher HH (1992d) Verbreitung und Ökologie von Neolamprologus buescheri. Die Aquarien- und Terrarienzeitschrift 45:305-310
Büscher HH (1993) Neolamprologus bifasciatus n. sp.: Ein neuer Tanganjikasee-Cichlide (Cichlidae, Lamprologini). Die Aquarien- und Terrarienzeitschrift 46:385-389

Büscher HH (1995) Ein neuer Cichlide von der zairischen Küste des Tanganjikasees. Neolamprologus variostig$m a$ n. sp. (Cichlidae, Lamprologini). Die Aquarienund Terrarienzeitschrift 48:794-797

Büscher HH (1995) Ein neuer Cichlide aus dem Tanganjikasee. Neolamprologus ventralis $\mathrm{n}$. sp. (Cichlidae, Lamprologini). Die Aquarien- und Terrarienzeitschrift 48:379-382

Büscher HH (1997) Ein neuer Cichlide aus dem Tanganjikasee: Neolamprologus helianthus (Cichlidae, Lamprologini). Die Aquarien- und Terrarienzeitschrift 50:701-706

Büscher HH (1998) Die Cichlidengemeinschaft von Tembwe (Kongo). Die Aquarien- und Terrarienzeitschrift 51:785-793

Büscher HH (1998) Eigenheim aus zweiter Hand: Buntbarsche in Schneckenhäusern. Die Aquarien- und Terrarienzeitschrift Sonderheft 6:51-59

Buston P (2003) Forcible eviction and prevention of recruitment in the clown anemonefish. Behav Ecol 14:576-582

Choe JC, Crespi BJ (1997) The evolution of social behavior in insects and arachnids. Cambridge University Press, Cambridge, $541 \mathrm{pp}$

Cockburn A (1998) Evolution of helping behavior in cooperatively breeding birds. Annu Rev Ecol Syst 29:141-177

Dickinson JL, Hatchwell BJ (2005) Fitness consequences of helping. In: Koenig W, Dickinson J (eds) Ecology and evolution of cooperative breeding in birds. Cambridge University Press, Cambridge, pp 48-66

Dierkes P., Taborsky M., Kohler U (1999) Reproductive parasitism of broodcare helpers in a cooperatively breeding fish. Behav Ecol 10:510-515

Dierkes P., Heg D., Taborsky M., Skubic E, Achmann R (2005) Genetic relatedness in groups is sex-specific and declines with age of helpers in a cooperatively breeding cichlid. Ecol Lett 8:968-975

Duffy JE, (1996) Eusociality in a coral-reef shrimp. Nature 381:512-514

Emlen ST (1997) Predicting family dynamics in social vertebrates. In: Krebs JR, Davies NB (eds) Behavioural ecology. An evolutionary approach. Blackwell, Oxford, pp 228-253

Goodwin NB, Balshine-Earn S, Reynolds JD (1998) Evolutionary transitions in parental care in cichlid fish. Proc Royal Soc Lond B 265:2265-2272

Grantner A, Taborsky M (1998) The metabolic rates associated with resting, and with the performance of agonistic, submissive and digging behaviours in the cichlid fish Neolamprologus pulcher (Pisces: Cichlidae). J Compar Physiol B 168:427-433

Heg D, Bachar Z, Brouwer L, Taborsky M (2004a) Predation risk is an ecological constraint for helper dispersal in a cooperatively breeding cichlid. Proc Royal Soc Lond B 271:2367-2374 
Heg D, Bender N, Hamilton I (2004b) Strategic growth decisions in helper cichlids. Proc Royal Soc Lond B 271:S505-508

Heg D, Bachar Z, Taborsky M (2005) Cooperative breeding and group structure in the Lake Tanganyika cichlid Neolamprologus savoryi. Ethology 111:1017-1043

Hattori A (1993) Social structure of a substrate-guarding cichlid, Julidochromis ornatus, and the influence of the territories of the algal feeder, Neolamprologus moorii, on its spacing behaviour. In: Nagoshi M, Yanagisawa $\mathrm{Y}$, Kawanabe $\mathrm{H}$ (eds) Ecological and limnological study on Lake Tanganyika and its adjacent regions VIII. Kyoto University Press, Kyoto. p 22

Kalas K (1976) Brutpflegehelfer und polygamie beim afrikanischen Buntbarsch Lamprologus brichardi. Naturwissenschaften 63:94

Katoh R, Munehara H, Kohda M (2005) Alternative male mating tactics of the substrate brooding cichlid Telmatochromis temporalis in Lake Tanganyika. Zool Sci 22:555-561

Kawanabe H, Hori M, Nagoshi M (1997) Fish communities in Lake Tanganyika. Kyoto University Press, Kyoto

Kohler U (1998) Zur Struktur und Evolution des Sozialsystems von Neolamprologus multifasciatus (Cichlidae, Pisces), dem kleinsten Schneckenbuntbarsch des Tanganjikasees. Shaker Verlag, Aachen

Komdeur J (1994) Experimental evidence for helping and hindering by previous offspring in the cooperativebreeding seychelles warbler Acrocephalus sechellensis. Behav Ecol Sociobiol 34:175-186

Kondo T, (1986) Feeding habits of Lamprologus savoryi (Teleostei: Cichlidae) with reference to its social behaviour. Physiol Ecol Jpn 23:1-15

Konings A (1998) Tanganyika cichlids in their natural habitat. Cichlid Press, El Paso, 272 pp

Kreiberg H (2000) Stress and anesthesia. In: Ostrander GK (ed) The laboratory fish. Academic Press, New York, pp 503-511

Kuwamura T, (1986) Parental care and mating systems of cichlid fishes in Lake Tanganyika: a preliminary field survey. J Ethol 4:129-146

Kuwamura T (1997) The evolution of parental care and mating systems among Tanganyikan cichlids. In: Kawanabe H, Hori M, Nagoshi M (eds) Fish communities in Lake Tanganyika. Kyoto University Press, Kyoto, pp 59-86

Ligon JD, Burt DB (2005) Evolutionary origins. In: Koenig W, Dickinson J (eds) Ecology and evolution of cooperative breeding in birds. Cambridge University Press, Cambridge, pp 5-34

Magrath RD, Johnstone RA, Heinsohn RG (2005) Reproductive skew. In: Koenig W, Dickinson J, (eds) Ecology and evolution of cooperative breeding in birds. Cambridge University Press, Cambridge, pp 157-176

Martin E, Taborsky M (1997) Alternative male mating tactics in a cichlid, Pelvicachromis pulcher: a comparison of reproductive effort and success. Behav Ecol Sociobiol 41:311-319

Mitchell JS (2003) Social correlates of reproductive success in false clown anemonefish: subordinate group members do not pay-to-stay. Evol Ecol Res 5:89-104
Ota K, Kohda M (2006) Description of alternative male reproductive tactics in a shell-brooding cichlid, Telmatochromis vittatus, in Lake Tanganyika. J Ethol 24:9-15

Rossiter A (1993) Studies on the biology of Neolamprologus multifasciatus. In: Nagoshi M, Yanagisawa Y, Kawanabe H (eds) Ecological and limnological study on Lake Tanganyika and its adjacent regions VIII. Kyoto University Press, Kyoto, p 32

Salzburger W, Baric S, Sturmbauer C (2002) Speciation via introgressive hybridization in East African cichlids? Mol Ecol 11:619-625

Sato T, Gashagaza MM (1997) Shell-brooding cichlid fishes of Lake Tanganyika: their habitats and mating systems. In: Kawanabe H, Hori M, Nagoshi M (eds) Fish communities in Lake Tanganyika. Kyoto University Press, Kyoto, pp 221-240

Schradin C, Lamprecht J (2000) Female-biased immigration and male peace-keeping in groups of the shelldwelling cichlid fish Neolamprologus multifasciatus. Behav Ecol Sociobiol 48:236-242

Schradin C, Lamprecht J (2002) Causes of female emigration in the group-living cichlid fish Neolamprologus multifasciatus. Ethology 108:237-248

Skubic E, Taborsky M, McNamara JM, Houston AI (2004) When to parasitize? A dynamic optimization model of reproductive strategies in a cooperative breeder. J Theor Biol 227:487-501

Solomon NG, French JA (1997) Cooperative breeding in mammals. Cambridge University Press, Cambridge, 402 pp

Stacey PB, Koenig WD (1990) Cooperative breeding in birds. Cambridge University Press, Cambridge, 615 pp

Staeck W, Linke H (1981) Afrikanische Cichliden II. Buntbarsche aus Ostafrika. Tetra Verlag, Melle, 199 pp

Stiassny MLJ (1997) A phylogenetic overview of the lamprologine cichlids of Africa (Teleostei, Cichlidae): a morphological perspective. South African J Sci 93:513-523

Stiver KA, Dierkes P, Taborsky M, Balshine S (2004) Dispersal patterns and status change in a cooperatively breeding fish: evidence from microsatellite analyses and behavioural observations. J Fish Biol 65:91-105

Sturmbauer C, Verheyen E, Meyer A (1994) Mitochrondrial phylogeny of the Lamprologini, the major substrate spawning lineage of cichlid fishes from Lake Tanganyika in eastern Africa. Mol Biol Evol 11:691-703

Sunobe T (2000) Social structure, nest guarding and interspecific relationships of the cichlid fish (Julidochromis marlieri) in Lake Tanganyika. African Study Monogr 21:83-89

Sunobe T, Munehara H (2003) Mating system and kin relationship between adults and young in the shellbrooding cichlid fish Neolamprologus meeli in Lake Tanganyika. J Ethol 21:87-92

Taborsky M (1984) Broodcare helpers in the cichlid fish Lamprologus brichardi: their costs and benefits. Animal Behav 32:1236-1252

Taborsky M (1985) Breeder-helper conflict in a cichlid fish with broodcare helpers: an experimental analysis. Behaviour 95:45-75 
Taborsky M (1994) Sneakers, satellites, and helpers: parasitic and cooperative behavior in fish reproduction. Adv Study Behav 23:1-100

Taborsky M, Hert E, von Siemens M, Stoerig P (1986) Social behaviour of Lamprologus species: functions and mechanisms. Annales Koninklijk Museum Midden-Afrika Zoologische Wetenschappen 251: 7-11

Taborsky M, Limberger D (1981) Helpers in fish. Behav Ecol Sociobiol 8:143-145
Woodland D (2002) Breeding Neolamprologus gracilis. Cichlid News Magazine 11:30-34

Yamagishi S (1988) Polyandry and helper in a cichlid fish Julidochromis marlieri. In: Kawanabe H, Kwetuenda MK (eds) Ecological and limnological study on Lake Tanganyika and its adjacent regions V. Kyoto University Press, Kyoto, pp 21-22

Yamagishi S, Kohda M (1996) Is the cichlid fish Julidochromis marlieri polyandrous? Ichthyol Res 43:469-471 